\title{
Emoções, stress, ansiedade e coping: estudo qualitativo com atletas de elite
}

\author{
Cláudia Dias ${ }^{1}$ \\ José Fernando Cruz ${ }^{2}$ \\ António Manuel Fonseca ${ }^{1}$
}

https://doi.org/10.5628/rpcd.09.01.09

\author{
${ }^{1}$ Centro de Investigação, Formação, \\ Inovação e Intervenção em Desporto $\left(\mathrm{CIFI}^{2} \mathrm{D}\right)$ \\ Faculdade de Desporto \\ Universidade do Porto \\ Portugal \\ ${ }^{2}$ Centro de Investigação em Psicologia (CiPsi) \\ Escola de Psicologia \\ Universidade do Minho
}

\section{RESUMO}

A influência dos factores e processos psicológicos no rendimento desportivo dos atletas está, de uma forma geral, amplamente demonstrada. No entanto, poucas investigações recorreram a uma metodologia qualitativa, a qual permite uma perspectiva mais detalhada e aprofundada das emoções e cognições dos atletas. Neste sentido, recorrendo a uma entrevista semi-estruturada, a presente investigação procurou, junto de 11 atletas portugueses de elite de vários desportos, com idades compreendidas entre os 22 e os 36 anos $(M=30.64 \pm 4.84)$, identificar as suas principais fontes de stress e ansiedade e as estratégias de coping a que recorriam em situações stressantes e/ou problemáticas, bem como explorar o papel de outras emoções no seu desempenho desportivo. Os resultados revelaram que: i) as principais fontes de stress estavam relacionadas com aspectos ligados à natureza da competição, pressões externas e ao seu próprio desempenho, sendo comuns a diferentes modalidades; ii) os atletas recorriam a diversas estratégias de coping em simultâneo, geralmente adaptativas, centradas na resolução de problemas e/ou na gestão das emoções; e iii) para além da ansiedade, outras emoções, positivas e negativas, pareciam influenciar o desempenho dos atletas.

Palavras-chave: stress, ansiedade, coping, emoções, atletas de elite, investigação qualitativa

\begin{abstract}
Emotions, stress, anxiety and coping: A qualitative study with elite athletes

The influence of psychological factors on athletes' sport performance is, in general, well documented. However, few investigations used a qualitative methodology, which gives a more detailed and profound perspective of athlete's emotions and cognitions. In this sense, using a semistructured interview with 11 Portuguese elite athletes from different sports, aged between 22 and $36(M=30.64 \pm 4.84)$, the present study aimed to identify their major sources of stress and anxiety and the coping strategies they used in problematic and stressful situations, as well as to explore the role of other emotions, other than anxiety, in competitive performance. The results showed that: i) the major sources of stress were common to the different sports, and were related with the nature of competition, external pressures and the athletes' performance; ii) the athletes used several coping strategies simultaneously, usually adaptative, either problem or emotion-focused; iii) in addition to anxiety, there were other positive and negative emotions that influenced athletes' performance.
\end{abstract}

Key-words: stress, anxiety, coping, emotions, elite athletes, qualitative research 


\section{INTRODUÇÃO}

Na última década, os métodos de investigação qualitativa têm vindo a receber cada vez mais atenção por parte dos investigadores no domínio da psicologia do desporto $(25,35)$ devido ao facto de, em grande medi$\mathrm{da}$, fornecerem uma perspectiva mais detalhada e aprofundada das emoções e cognições dos atletas, comparativamente aos métodos quantitativos ${ }^{(11)}$. Por exemplo, o recurso a entrevistas, ao permitir que o sujeito descreva com as suas próprias palavras os eventos que ocorrem naturalmente e o modo como se relacionam com as variáveis em análise, proporciona uma profundidade e riqueza de informação adicional que não é conseguida com as medidas de auto-relato geralmente utilizadas em estudos quantitativos, facilitando assim, naturalmente, uma melhor compreensão dos seus estados psicológicos. Desta forma, esta abordagem pode ser especialmente útil na identificação de novas variáveis e relações em áreas não exploradas ou na obtenção de avaliações exaustivas das emoções e cognições dos atletas(18). Neste contexto, diversos investigadores, enquanto advertem para o excesso de confiança depositado na informação quantitativa, encorajam o recurso a abordagens qualitativas na investigação de fenómenos relacionados com o rendimento e excelência desportiva. É o caso, por exemplo, da investigação da ansiedade competitiva e da sua relação com o desempenho desportivo(e.g., 15, 32), ou do estudo das competências de coping utilizadas pelos atletas em situações problemáticas e/ou stressantes (e.g., 24).

No que respeita à relação ansiedade- rendimento em particular, Gould e Krane ${ }^{(18)}$ enfatizaram de forma clara os pontos fortes das entrevistas aprofundadas com atletas e advogaram que os investigadores devem considerar seriamente tal abordagem, uma vez que os estudos quantitativos realizados neste domínio específico tendem a centrar-se unicamente na identificação dos sintomas. Por outro lado, investigações que têm recorrido a metodologias qualitativas, nomeadamente entrevistas, têm-se preocupado em identificar as causas/ fontes de ansiedade. De uma forma geral, estas investigações têm identificado um vasto leque de fontes gerais de stress, incluindo padrões de alto rendimento baseados em exigências potenciais e ambientais, pressões de outros significativos (familiares, treinadores, dirigentes, imprensa, etc.) e aspectos relacionados com a natureza da competição e com a avaliação social(e.g., 15, 17, 26, 33).

Adicionalmente, os métodos de investigação qualitativa foram também preferidos por muitos investigadores para averiguarem as estratégias de coping utilizadas pelos atletas no confronto com situações stressantes e/ ou problemáticas(e.g., 1, 15, 16, 24). A este nível, não obstante alguns estudos terem concluído que muitas das estratégias de coping identificadas já tinham sido descritas na literatura existente, nomeadamente em estudos quantitativos, foram encontradas algumas estratégias específicas às exigências e contexto da modalidade em questão(e.g., 24), as quais, por essa razão, não são medidas pelos instrumentos geralmente usados para avaliar o coping no desporto [e.g., Ways of Coping Checklist ${ }^{(6)}$; COPE Inventory $\left.{ }^{(7)}\right]$. Nesta medida, análises indutivas de entrevistas relacionadas com as estratégias de coping usadas por atletas poderão revelar estratégias específicas que surgem da sua interacção com o ambiente social e que, posteriormente, poderão contribuir para o desenvolvimento de instrumentos de avaliação contextualmente sensíveis.

Por último, é também importante salientar a importância crescente da exploração do papel de outras emoções, para além da ansiedade, no rendimento dos atletas, um domínio ainda muito pouco explorado na psicologia do desporto, especialmente a nível nacional, e que tem suscitado, especialmente nos últimos anos, o interesse de diversos investigadores(e.g., 7, 19, 21, 22, 23, 30, 31). Com efeito, parece que a psicologia do desporto começa a despertar para a ideia de que a investigação centrada, isoladamente, na variável da ansiedade, é insuficiente para abranger as reacções emocionais dos atletas, começando a considerar-se "a complexidade da vida emocional em contextos desportivos"(9, p. 204), por exemplo no que se refere ao papel e influência de outras emoções negativas e positivas (e.g., irritação/ raiva, felicidade/ alegria, culpa, medo, vergonha) no desempenho desportivo. Neste contexto, uma análise mais aprofundada desta temática poderá promover uma compreensão mais aprofundada da influência de diferentes emoções no rendimento e comportamento desportivo dos atletas; para além disso, poderá contribuir para "lançar os alicerces" para o 
futuro desenvolvimento de instrumentos válidos para avaliar as emoções no desporto.

Em suma, o presente estudo, ao recorrer a uma metodologia qualitativa, designadamente a entrevista, pretendeu preencher algumas lacunas inerentes ao recurso a instrumentos de auto-relato (decorrentes de uma abordagem predominantemente quantitativa), procurando identificar, junto de atletas portugueses de elite, as principais fontes de stress e ansiedade, as estratégias de coping mais utilizadas e, ainda, as principais emoções experienciadas.

\section{MATERIAL E MÉTODOS}

\section{Sujeitos}

Participaram neste estudo 11 atletas, 9 do sexo masculino e 2 do sexo feminino, com idades compreendidas entre os 22 e os 36 anos $(M=30.64 \pm 4.84)$, representando vários desportos: ténis $(\mathrm{n}=2)$, andebol $(n=3)$, voleibol $(n=2)$, hóquei em patins $(n=2)$, basquetebol $(n=1)$ e atletismo $(n=1)$.

Atendendo aos objectivos deste estudo, foram considerados atletas que, durante a sua carreira desportiva, tivessem obtido, pelo menos uma vez, uma classificação entre o $1^{\circ}$ e o $3^{\circ}$ lugar em Campeonatos Internacionais (Europa, África ou Mundo) e/ ou uma classificação até ao $5^{\circ}$ lugar em Jogos Olímpicos. Em relação ao ténis (ao qual não era possível aplicar os critérios anteriormente referidos), foram escolhidos atletas que estavam ou tinham estado classificados nas tabelas internacionais da modalidade (i.e., Women Tennis Association e Professional Tennis Association).

\section{Instrumentos e procedimentos}

Para a realização deste estudo, os dados foram recolhidos através de uma entrevista semi-estruturada e de resposta aberta, desenvolvida com base no protocolo de entrevista de Taylor e Schneider( ${ }^{(34)}$. O guião usado abrangia aspectos relacionados com: (i) fontes de stress e ansiedade; (ii) estratégias de coping; e (iii); outras emoções (para além da ansiedade), com influência no rendimento.

Em todas as entrevistas foi assegurada a confidencialidade e anonimato dos dados e recebida autorização para gravação das mesmas. As entrevistas realizaram-se em locais reservados (de forma a evitar influência de terceiros), tendo durado entre 90 e 120 minutos. No decorrer da entrevista, a entrevistadora adoptou uma postura não crítica e não avaliativa, intervindo apenas quando fosse estritamente necessário esclarecer alguma afirmação ou ponto de vista.

\section{Análise dos dados}

A análise de conteúdo foi efectuada de acordo com os procedimentos sugeridos por especialistas em metodologia da investigação qualitativa e da análise de conteúdo dos mais variados contextos, incluindo o desportivo $(14,17,33)$. Esta análise qualitativa obedeceu ainda a alguns princípios fundamentais, sendo realizada em quatro etapas sucessivas: (i) transcrição das entrevistas na sua totalidade; (ii) leitura e análise cuidada (incluindo segunda e terceira leituras) das situações descritas, por parte de um painel de cinco psicólogos do desporto, familiarizados com este tipo de análise metodológica; (iii) identificação e descrição ("em bruto") de temas específicos descritos pelos atletas; e (iv) análise indutiva dos temas identificados pelo painel de juízes, posteriormente agrupados em dimensões mais globais. De salientar que esta análise indutiva permite que temas e dimensões gerais possam ser criados a posteriori, a partir da interpretação lógico-semântica do texto(11). Na primeira etapa, a transcrição das entrevistas foi efectuada de forma a reproduzir fielmente o discurso dos atletas, no sentido de tratar e organizar as entrevistas, que se encontravam em estado bruto, para uma forma coerente e lógica.

$\mathrm{Na}$ segunda fase, as entrevistas foram sujeitas a uma leitura prévia que tinha por objectivo dar uma ideia global do que foi respondido, sendo posteriormente realizadas segunda e terceira leituras, atentas e cuidadas. Pretendia-se, com este procedimento, identificar significados e procurar uma coerência que permitisse elaborar o raciocínio e organizar as informações fornecidas pelos participantes. Com base nestas leituras, foi possível realizar uma interpretação lógicosemântica do conteúdo das respostas, que permitiu identificar e/ ou descrever temas específicos que representavam situações ou resumos das principais ideias referidas nas respostas.

Num último momento, fez-se o agrupamento dos temas específicos com significados idênticos em dimensões mais gerais (em algumas questões os sujeitos referiram mais do que uma dimensão geral). 
Como critério de inclusão de uma resposta numa dimensão, foi definida a obrigatoriedade de todos os psicólogos do desporto que integravam o painel de investigadores assim o terem considerado. Nos casos em que não existiu concordância entre os membros do painel, a selecção da dimensão na qual a resposta foi incluída foi efectuada a partir de reflexão conjunta, sendo as transcrições reanalisadas até se chegar a um consenso. Neste caso, o ponto de vista da entrevistadora foi considerado especialmente relevante nas discussões interpretativas, na medida em que possuía a vantagem de ter entrevistado e conversado directamente com todos os participantes do estudo. Por último, importará referir que a discussão dos resultados, que a seguir se apresenta, foi realizada com base nas dimensões gerais definidas para cada uma das quatro questões colocadas aos atletas, com o objectivo de fazer evidenciar as conclusões mais significativas.

\section{APRESENTAÇÃO E DISCUSSÃO DOS RESULTADOS} As principais fontes de stress e ansiedade

No que diz respeito às fontes de stress e ansiedade competitiva experienciadas pelos atletas, os resultados da análise qualitativa permitiram identificar dez dimensões gerais: (i) avaliação social/ preocupações de auto-apresentação; (ii) comparação com o adversário; (iii) factores extra-desportivos; (iv) falta de apoio social; (v) não ter o desempenho esperado; (vi) natureza da competição; (vii) percepção de falta de prontidão física, técnica e/ ou táctica; (viii) pressões externas; e (ix) outras (ver Quadro 1).

As fontes de stress mais frequentemente assinaladas pelos atletas estavam relacionadas com a 'natureza da competição', 'pressões externas' e 'não ter o desempenho esperado', sendo também assinalados com relativa frequência os aspectos relacionados com a 'avaliação social/ preocupações de auto-apresentação' e a 'comparação com o adversário'. A dimensão 'natureza da competição' incluía aspectos associados à importância, dificuldade, novidade $\mathrm{e}$ nível competitivo, sendo a importância da competição a mais frequentemente assinalada.
Agora, aquilo que me parecem ser as fontes mais importantes, é a importância do jogo, a importância desportiva do jogo; é um campeonato que se decide naquele momento, é defender uma posição classificativa...

Atleta 2

O stress vem com a dificuldade, com jogos difíceis...

Atleta 10

A importância do jogo, tipo se for uma final de um torneio importante.

Atleta 4

Qualquer final, qualquer título que está em jogo, há esse stress.

Atleta 8

Todos os jogos que sejam a decidir, tipo final do Campeonato do Mundo, final do Campeonato da Europa, são sempre os que sentimos mais pressão.

Atleta 3

No que respeita às 'pressões externas', esta dimensão compreendia referências a familiares, amigos, dirigentes, treinadores, público e imprensa, tendo alguns atletas referido a pressão simultânea de mais do que um destes grupos.

Eu acho que isso tudo junto acaba por causar alguma pressão. Os amigos, a família, a imprensa.

Atleta 11

...das pessoas que convivem connosco.

Atleta 3

...familiares talvez, também sinto um bocado, se forem familiares que eu não estou habituada a que vejam os jogos, ou qualquer coisa, também influencia.

Atleta 4

...o treinador que esteja a ver...

Atleta 4

...quem esteja a ver, quem esteja a assistir ao jogo, também pode ser uma fonte...pessoas... 
Quadro 1. Dimensões gerais e temas específicos das situações ou acontecimentos geradores

de elevados níveis de stress, pressão ou ansiedade e frequência de atletas que as referem.

\begin{tabular}{|c|c|c|c|}
\hline $\begin{array}{l}\text { Atletas que } \\
\text { referem a } \\
\text { dimensão } \\
n\end{array}$ & $\%$ & Dimensões gerais & Temas específicos \\
\hline 9 & 81.8 & Natureza da competição & $\begin{array}{l}\text { importância da competição } \\
\text { dificuldade da competição } \\
\text { novidade da competição } \\
\text { nível da competição }\end{array}$ \\
\hline 8 & 72.7 & Pressões externas & $\begin{array}{l}\text { pressão treinador/ dirigentes } \\
\text { pressão amigos/ família } \\
\text { pressão imprensa/patrocinadores } \\
\text { pressão público }\end{array}$ \\
\hline 7 & 63.6 & Não ter o desempenho esperado & $\begin{array}{l}\text { não atingir objectivos } \\
\text { perder ou não ganhar } \\
\text { preocupações com o rendimento }\end{array}$ \\
\hline 6 & 54.6 & Avaliação social/ preocupações de auto-apresentação & $\begin{array}{l}\text { preocupações direccionadas para outros significativos } \\
\text { (não decepcionar os outros; agradar e impressionar os } \\
\text { outros) } \\
\text { críticas de outros significativos }\end{array}$ \\
\hline 5 & 45.5 & Comparação com o adversário & competir contra adversários mais "fortes"/ melhores \\
\hline 4 & 36.4 & Outras & $\begin{array}{l}\text { preparar-se para um objectivo a longo prazo } \\
\text { questões não resolvidas num pavilhão } \\
\text { exigências competitivas ambientais (distância) } \\
\text { questões contratuais }\end{array}$ \\
\hline 3 & 27.3 & Factores extra-desportivos & $\begin{array}{l}\text { questões financeiras } \\
\text { questões pessoais e/ou familiares }\end{array}$ \\
\hline 2 & 18.2 & Falta de apoio social & $\begin{array}{l}\text { ambiente hostil } \\
\text { ninguém conhecido ver o jogo }\end{array}$ \\
\hline 2 & 18.2 & Percepção de falta de prontidão física, técnica e/ ou táctica & má preparação física, técnica e/ ou técnica \\
\hline
\end{tabular}

Na dimensão 'não ter o desempenho esperado' as afirmações encontravam-se relacionadas com preocupações em perder ou não ganhar, não atingir os objectivos desportivos e com o rendimento de uma forma geral.

... a minha preocupação é como é que vai decorrer o jogo.

Atleta 9 Ou seja, é pensar: "Bem, não podemos fazer isto, porque

Não ganhar, perdermos, não atingirmos os objectivos... não podemos decepcionar este, este, este...”

Saliente-se ainda a 'avaliação social/ preocupações de auto-apresentação', uma dimensão que abrangia preocupações dos atletas em não decepcionar as outras pessoas, especialmente outros significativos, e que se traduzia por preocupação em estar à altura das expectativas e esperanças depositadas neles.

Atleta 8

Atleta 3 
As expectativas, talvez... As expectativas de muitas pessoas em relação a mim sempre foi uma coisa que existiu desde muito novo, sempre fui um bocado falado, que era prodígio, tive resultados muito, muito novo, portanto, desde 12 anos, 11, já tinha resultados muito bons, nos meus escalóes $e$, portanto, desde aí até ao fim da minha carreira tive sempre esse rótulo e quando jogava bem era normal porque era muito talentoso e era um prodígio, quando jogava mal era sempre o factor psicológico que falhava. Era um rótulo fácil, mas... havia realmente várias situações de tensão.

Atleta 5

...no dia a seguir, as pessoas, por exemplo, no meu caso, às vezes tenho que me preocupar, embora não me preocupe muito com o estatuto que tenho e que as pessoas esperam de mim determinada prestação. Isso também acaba por ser uma fonte de pressão, porque eu também espero de mim, eu conquistei um estatuto, um estatuto social e um estatuto financeiro dentro da equipa, que se não tiver o desempenho que as pessoas esperam de mim, ponho em causa todo o estatuto que adquiri, isso é uma relação normal que existe no desporto e na vida, não é? Tu tens um emprego A, adquires um certo estatuto financeiro, um certo estatuto na empresa, tens que trabalhar para manter esse estatuto $e$ nós, como desportistas, passa-se precisamente da mesma maneira, se possível incrementá-lo.

Atleta 7

Finalmente, refira-se a importância dada à 'comparação com o adversário', um factor que se constituía como fonte de stress e ansiedade quando os atletas sentiam que o oponente era superior a eles próprios.

Muitas vezes o stress é maior quando sentimos alguma incapacidade perante o adversário.

Atleta 2

...talvez o tipo de adversária, normalmente quando eu jogo com adversárias estrangeiras e que têm um melhor ranking que eu, eu vou sempre mais descontraída, tipo, naquela: "Vou dar o meu máximo". Quando são adversárias portuguesas ou que têm pior ranking que eu, vou um bocado mais pressionada.

Atleta 4

As fontes de stress identificadas parecem assim ir de encontro a diversas investigações de cariz qualitativo realizadas anteriormente neste domínio por diversos investigadores(e.g., 1, 17, 26)

Com efeito, num estudo de James e Collins(26) com atletas de diversas modalidades, colectivas e individuais, as principais fontes de stress referiam-se a pressões de outros significativos, factores relacionados com a natureza da competição e preocupações de avaliação social e auto-apresentação. Paralelamente, em estudos de Gould et al. com lutadores(14) e patinadores de elite(17), algumas das fontes de stress mais citadas estavam relacionadas com expectativas e pressão para um bom rendimento e exigências físicas, psicológicas (stress competitivo e dúvidas sobre si próprio) e ambientais (exigências temporais, dos media e stress financeiro) aos recursos do atleta. Por último, investigações de Jones et al. $(27,28)$ mostraram a relevância da percepção de prontidão, da expectativa dos resultados, da importância da competição e dos factores ambientais.

Ou seja, de uma forma geral, as fontes de stress reportadas em diferentes investigações são consistentes com as fontes de stress identificadas na presente investigação. Porém, a análise dos dados sugeriu também a necessidade de se ter em linha de conta outras fontes de stress e ansiedade relacionadas, por exemplo, com a percepção de falta de preparação para a competição, exigências ambientais, falta de apoio social durante a competição, ou até com questões não directamente relacionadas com a competição, como o facto de o clube ainda não ter renovado o contrato ao/ à atleta ou, ainda, problemas familiares e pessoais.

\section{As estratégias de coping com o stress e a ansiedade}

Relativamente às estratégias de coping utilizadas em situações problemáticas e/ ou stressantes, os resultados das análises às respostas dos atletas, apresentados no Quadro 2, permitiram identificar treze dimensões principais: (i) aceitação; (ii) apoio emocional/ social; (iii) apoio instrumental; (iv) autocontrolo emocional/ redução da tensão; (v) autoculpabilização; (vi) autodistracção; (vii) coping activo; (viii) coping confrontativo; (ix) desistir/ desinvestir; (x) isolamento; (xi) planeamento; (xii) reavaliação positiva da situação; e (xiii) religião.

As estratégias de 'coping activo' e de 'reavaliação positiva das situações' pareciam ser as mais utilizadas pelos atletas, seguidas do 'planeamento'; outra estratégia de coping psicológico também utilizada com relativa frequência dizia respeito à 'aceitação' das situações problemáticas. 
Quadro 2. Dimensões gerais e temas específicos das estratégias de coping para lidar com

situações geradoras de stress, ansiedade ou pressão e frequência de atletas que as referem.

\begin{tabular}{|c|c|c|c|}
\hline $\begin{array}{l}\text { Atletas que } \\
\text { referem a } \\
\text { dimensão } \\
\quad \mathrm{n}\end{array}$ & $\%$ & Dimensão geral & Temas específicos \\
\hline 8 & 72.7 & Coping activo & $\begin{array}{l}\text { esforço e trabalho } \\
\text { tentativa activa de resolução do problema/ situação } \\
\text { procura de alternativas ou soluções/correcção de erros } \\
\text { concentração e envolvimento no jogo } \\
\text { lutar/ não desistir }\end{array}$ \\
\hline 8 & 72.7 & Reavaliação positiva da situação & $\begin{array}{l}\text { autoverbalizações e pensamentos positivos } \\
\text { procurar ver a situação de outra perspectiva } \\
\text { procura de estímulos positivos de actuações passadas } \\
\text { recordação de experiências anteriores (experiência) }\end{array}$ \\
\hline 6 & 54.6 & Planeamento & $\begin{array}{l}\text { definir tipo de objectivos a atingir } \\
\text { definir passos a dar, tarefas a concretizar }\end{array}$ \\
\hline 5 & 45.5 & Aceitação & $\begin{array}{l}\text { aceitar que as coisas acontecem } \\
\text { resignação } \\
\text { conformismo }\end{array}$ \\
\hline 3 & 27.3 & Apoio emocional/social & $\begin{array}{l}\text { receber apoio emocional do conjugue/ namorado(a) } \\
\text { receber apoio emocional da família e/ ou amigos } \\
\text { receber apoio emocional dos colegas de equipa }\end{array}$ \\
\hline 3 & 27.3 & Autocontrolo emocional/ redução da tensão & $\begin{array}{l}\text { ouvir música } \\
\text { relaxamento } \\
\text { manter a calma }\end{array}$ \\
\hline 3 & 27.3 & Desistir/desinvestir & desligar-se do jogo \\
\hline 2 & 18.2 & Apoio instrumental & receber conselhos do treinador ou director \\
\hline 2 & 18.2 & Autodistracção & $\begin{array}{l}\text { esquecer, pensar noutra coisa } \\
\text { abstrair-se } \\
\text { envolver-se noutras actividades }\end{array}$ \\
\hline 2 & 18.2 & Coping confrontativo & $\begin{array}{l}\text { agressão e/ou insulto } \\
\text { reclamar/protestar }\end{array}$ \\
\hline 1 & 9.1 & Autoculpabilização & culpar-se a si próprio pelas derrotas/erros \\
\hline 1 & 9.1 & Isolamento & isolamento de outras pessoas \\
\hline 1 & 9.1 & Religião & confiar em Deus \\
\hline
\end{tabular}

Os atletas que recorriam ao 'coping activo' iniciavam acções directas para lidar com a situação problemáti$\mathrm{ca}$, o que se traduzia num incremento do esforço, ou do trabalho, e na procura de soluções alternativas; por outras palavras, não desistiam de procurar resolver o problema. ...vamos trabalhar aquilo que falhamos (...) insistir um bocadinho mais naquilo...

Atleta 10

...tenho que trabalhar mais porque algo está mal, tenho que melhorar porque algo está mal. Às vezes não cumpri- 
mos com as directrizes ou com os sistemas tácticos que estão definidos e o incumprimento ás vezes leva a derrotas, muitas vezes...

Atleta 9

Tentar continuar a lutar, não sei... lutar, penso nisso, continuar a lutar (...) é isso que eu penso; 'Vou tentar dar a volta...'

Atleta 4

O recurso ao 'planeamento', por sua vez, envolvia a tentativa de definição, perante um problema, de uma estratégia de resolução para o mesmo.

Para que aconteça o que eu quero tenho que fazer isto, isto, isto e isto"; "Tenho que focalizar este jogador assim e focar aquele assim”, ou seja., nos pensamentos antes.

Atleta 8

...tento pensar nos objectivos que eu tenho, tipo os objectivos que eu quero atingir.

Atleta 4

...tento-me concentrar naquilo que será a minha tarefa e a tarefa do grupo; dificuldades que eu possa eventualmente encontrar, tentar pensar um pouco naquilo que eu terei que fazer no jogo.

Atleta 7

Geralmente, os atletas que recorriam à 'reavaliação positiva' procuravam algo de bom e positivo no que estava a acontecer, isto é, tentavam ver as situações problemáticas pelas quais estavam a passar numa perspectiva diferente, de forma mais positiva. Para manter um pensamento positivo, os atletas recorriam a diversas estratégias, entre as quais o uso de verbalizações positivas ou visualização mental e recordação de experiências anteriores positivas.

É um pouco isso, é ter o tal pensamento positivo. Um médico amigo meu, a certa altura dizia-me assim: "Pá, vocês pensam sempre que a garrafa está meia vazia, mas ela não está meia vazia, ela está meia cheia”. Eu, na minha posição particular, sou um finalizador, sou um 'ponta'. Eu sei que vou defrontar um grande guarda-redes, e sei, por experiências anteriores, que falhei remates... se eu me concentrar nos remates que falhei, não saio dali, porque não encontro soluções, porque falhei... Ele levantou a perna ali e eu bati com a bola lá, ele fechou, etc.. Mas eu entretanto penso desta forma: "Não, atenção que eu já fiz isto, isto, isto e isto e deu..."; muitas vezes acontece-me isso. Há guardaredes com que tenho mais alguma dificuldade em finalizar, em ultrapassá-los e "jogo" um pouco com essa situação: "Não, calma, então, eu falhei assim, mas também marquei assim, eu já marquei daquela forma... portanto, eu não sou incapaz do o fazer, vamos lá!”

Atleta 2

Eu quando estou nervosa penso sempre positivo, penso para mim, penso que não vou perder mais, que não vou perder com aquela, e que vou ganhar e que isto é o meu campeonato; acho que penso positivo quando estou nervosa. Também transpiro um bocadinho, mas é positivo, tudo é positivo, acho que sim, é normal uma pessoa quando está stressada transpirar-se, acho eu, para mim é; principalmente das mãos, transpiro mais das mãos quando estou stressada $e$ fico fria; transpiro e fico com frio.

Atleta 6

Um dado interessante prende-se com o facto de muitos atletas terem referido que a 'aceitação' da situação problemática ou stressante era, frequentemente, um "ponto de partida" essencial no processo de coping, na medida em que só depois de aceitarem a situação conseguiam, de alguma forma, tentar lidar com a mesma.

Em relação aos anos que já andamos a jogar pode ser um defeito aceitar que as coisas acontecem, "isto acontece, está a acontecer"; (...) pode ser um defeito, mas também é uma forma de não ligar...

Atleta 2

Pára um segundo e pensa: esse golo já não podes fazer nada, por muito mau que tenha sido, o maior frango que tenha sido, esse golo ninguém vai poder apagá-lo, esse golo está no marcador...

Atleta 8

De uma forma geral, as estratégias de coping identificadas na presente investigação são congruentes não só com investigações de cariz mais quantitativo realizadas anteriormente(e.g., 2, 7, 13, 20), mas também com investigações qualitativas desenvolvidas com atletas de elite(e.g., 2, 10, 15, 16, 24). 
Mais concretamente, numa investigação realizada por Barbosa e Cruz ${ }^{(2)}$ com andebolistas portugueses, os autores concluíram que as estratégias mais utilizadas eram a resolução planeada de problemas (um misto de coping activo e planeamento) e a reavaliação positiva das situações. Paralelamente, no seu estudo com lutadores olímpicos de luta livre, Gould et al.(15) também constataram que aqueles atletas recorriam preferencialmente a estratégias activas e de planeamento para lidarem com situações problemáticas. Além disso, quer nesta investigação com lutadores, quer num estudo posterior com patinadores ${ }^{(16)}$, os autores constataram que uma das estratégias de coping utilizada por maior número de sujeitos era a visualização mental, geralmente no âmbito da reavaliação positiva das situações. De forma similar, Dale ${ }^{(10)}$ verificou que a visualização mental era uma das estratégias mais referidas por atletas de decatlo para lidarem com distracções e, posteriormente, Holt e Hogg (24) concluíram que recordar desempenhos anteriores positivos ou usar verbalizações positivas também se encontravam entre as estratégias preferidas por jogadoras de futebol de elite para lidarem com exigências competitivas.

Em suma, à semelhança dos lutadores e patinadores $(15,16)$, dos atletas de decatlo de Dale ${ }^{(10)}$, das futebolistas de Holt e Hogg(24) e dos andebolistas de Barbosa e Cruz(2), os atletas deste estudo pareciam ser muito eficazes na sua capacidade de recorrerem ao coping activo, ao planeamento das situações e à avaliação e reavaliação de várias situações no sentido de determinarem que necessitavam de alterar os seus pensamentos ou comportamentos actuais para lidarem melhor com situações stressantes e/ ou problemáticas.

Adicionalmente, à semelhança de investigações anteriores de Gould et al.(15), os atletas não recorriam unicamente a estratégias que lhes permitissem lidar com o problema/ stressor, tentando também lidar com emoções perturbadoras geradas pela situação problemática. O apoio social, por exemplo, era uma estratégia à qual os atletas participantes neste estudo recorriam quer para regular as emoções (e.g., conversar com pessoas que os ajudavam a sentiremse melhor) quer para tentar encontrar uma solução para o problema (e.g., procurar conselhos de outras pessoas), o que, de resto, confirma a importância dada à estratégia de coping por diversos investigadores(e.g., 7, 16, 30). Neste contexto, Folkman e Lazarus(12) salientam o valor do apoio social como uma importante estratégia de coping a ser cultivada e conservada, podendo ser utilizada de forma distinta por diferentes pessoas.

Além disso, ao mostrarem que os atletas recorriam simultaneamente a mais do que uma estratégia de coping, estes resultados vão ao encontro do que foi alertado por Gould et al.(15), que, ao depararem-se com este dado na anteriormente referida investigação com lutadores olímpicos, sustentaram que " $a$ observação de que os lutadores identificam mais do que uma estratégia de coping é consistente com a noção de que o coping é um processo dinâmico, complexo"(15, pp. 86-87). Por último, saliente-se que não obstante a maior parte das estratégias identificadas ser positiva, houve também referência a comportamentos de coping teoricamente menos eficazes, um resultado que também tinha sido evidente noutras investigações(e.g., 5). Assim, apesar de ter sido encorajador notar que a maioria das estratégias de coping utilizadas pelos atletas de elite deste estudo era adaptativa (e.g., coping activo, planeamento, reavaliação positiva), os comportamentos de coping desadaptativos identificados (e.g., coping confrontativo, isolamento) sugerem que, mesmo com atletas de elite, devem ser efectuados esforços para educar e fornecer apoio psicológico a atletas que recorrem a comportamentos de coping menos eficazes e potencialmente desajustados ou inadequados.

\section{As emoções}

No quadro 3, são apresentadas as emoções, para além da ansiedade, que os atletas consideraram influenciar o seu rendimento, e que incluem: (i) a felicidade-alegria/ bem-estar; (ii) a frustração; (iii) a irritação/ raiva; (iv) o medo; (v) o orgulho; (vi) a tristeza; e (vii) a vergonha. De todas estas emoções, a 'irritação/raiva' e a 'felicidade/alegria' foram referidas por mais atletas, sendo o 'medo' mencionado por um número mais reduzido de atletas.

Como se pode constatar nos exemplos seguintes, de um modo geral, os atletas consideraram a 'vergonha', o 'medo', a 'tristeza' e a 'frustração' negativos. 
Quadro 3. Dimensões gerais e temas específicos das emoções e frequência de atletas que as referem

\begin{tabular}{|c|c|c|c|}
\hline $\begin{array}{c}\text { Atletas que } \\
\text { referem a } \\
\text { dimensão } \\
n\end{array}$ & $\%$ & Dimensão geral & Temas específicos \\
\hline 6 & 54.6 & Irritação/ raiva & $\begin{array}{l}\text { irritação } \\
\text { raiva }\end{array}$ \\
\hline 5 & 45.5 & Felicidade-alegria/ bem-estar & $\begin{array}{l}\text { bem-estar } \\
\text { alegria }\end{array}$ \\
\hline 4 & 36.4 & Medo* & $\begin{array}{l}\text { medo de falhar } \\
\text { medo de perder }\end{array}$ \\
\hline 3 & 27.3 & Frustração & sentir-se frustrado(a) \\
\hline 2 & 18.2 & Vergonha & vergonha \\
\hline 2 & 18.2 & Tristeza & $\begin{array}{l}\text { decepção } \\
\text { tristeza }\end{array}$ \\
\hline 1 & 9.1 & Orgulho & sentimento de orgulho \\
\hline
\end{tabular}

Vergonha já senti uma vez, fiquei cá para trás, senti vergonha na prova $x$; foi a seguir ao outro Campeonato da Europa (...), estavam à espera de mim uma coisa e saiu outra, senti vergonha porque fiquei mesmo cá para trás e senti vergonha porque não lutei, podia a menos acabar, não dei o meu limite; foi uma prova mesmo... fui para lá, comecei bem e depois desliguei do pelotão e desliguei de tudo, parecia que estava a passear lá nas ruas (...), só para acabar a prova...senti vergonha, é negativo.

Atleta 6

Foi um acumular de vergonha, uma frustração, a vergonha por aquilo estar a decorrer da forma que estava a decorrer $e$ estarmos a perder com um adversário que nunca foi, nem é, nem será mais forte do que nós...

Atleta 2

É medo, eu tenho muito medo, medo de perder com portuguesas.

Atleta 6

...medo de perder alguns jogos
Durante a competição, pronto, o receio é mais de uma pessoa continuar a falhar...

Atleta 7

E uma pessoa está triste... há milhentas situações que podem suceder, para ficarmos tristes: uma pessoa ter um compromisso e saber que não o vai poder cumprir na sua vida; ter um filho doente; uma pessoa zangar-se com a namorada, zangar-se com a mulher; ter uma chatice com o pai; o pai doente, tanta coisa, não é? Nós sofremos precisamente... nós somos humanos, não é? Todos os problemas que um ser humano tem, no seu dia-a-dia no trabalho, um problema com um colega, um problema com o patrão, neste caso o treinador ou o director; todo este tipo de situações podem influenciar negativamente a situação. Eu já tive, por exemplo, não tive assim casos em que me sentisse triste derivado a um problema destes, só relativamente, pronto, a um problema de saúde, ou sentir-me um pouco mais triste nesse aspecto, felizmente eu nunca tive assim problemas com colegas, nem com treinadores, nem com directores, mas sei de colegas que tiveram e, pronto, foi muito difícil, tentei ser aquela mão, dar incentivo, tentar modificar um pouco aquele dia menos bom dessa pessoa; algumas vezes conseguia, outras vezes não conseguia.

Atleta 7 
De forma negativa, a frustração, estar chateada, amuada e irritada, a irritação; começo a jogar e as coisas não estão a correr bem, normalmente o que eu sinto mais é frustração, que é ainda pior, ainda piora as coisas, frustração e estar negativa, estar sempre a dizer coisas negativas e se não corre bem, em vez de tentar continuar, a mudar as coisas...não deixar andar.

Atleta 4

Por outro lado, a 'irritação/ raiva' foi considerada positiva por alguns atletas e negativa por outros.

Agora, eu, por exemplo, gosto de estar irritado, gosto de me enervar, gosto de me chatear, para mim é positivo; a pior coisa e andar lá e aparentar cá para fora tranquilidade, é quando eu estou pior, é quando me sinto pior..

Atleta 3

Eu (...) prefiro estar irritado (...), ou seja, prefiro discutir com o árbitro com um adversário entrar numa pequena zanga num dado momento, isso não me tira da concentração. (...) O irritar-me com um adversário não me tira da concentração, discuto porque sei como estou a discutir e sei que me vai haver um cartão amarelo e acabará, e acaba a coisa.

Atleta 8

...tinha muitas vezes raiva (...), sempre fui muito agressivo, sou uma pessoa agressiva, não é violenta no mau sentido, mas sempre fui muito temperamental. Havia alturas que aquilo se controlava mais ou menos, mas havia alturas em que saía um bocado do controlo no jogo, mas nunca fui uma pessoa com problemas ou com falta de emoções... nunca fui (...), mas tinha muitas vezes raiva, depois às vezes tinha que me irritar um bocado...

Atleta 2

A irritação...só fico irritada durante a prova quando me dão encontrões, é mau porque estraga logo tudo, eu não gosto de levar encontrões durante a prova, fico logo desconcentrada, sei lá...

Atleta 6

Já a 'felicidade/ alegria' era vista como positiva e associada quer com alegria quer com bem-estar.
... a alegria a jogar, prazer de estar a jogar (...), acho que é isso. São positivas porque me ajudam a ganhar, o estar alegre...

Atleta 4

Por último, o único atleta que fez referência ao 'orgulho', definiu esta emoção de forma ambivalente, como uma "espada de dois gumes".

O orgulho é bom por um lado e por outro não; é mau porque vou sentir também mais pressão, porque as pessoas vão esperar mais de mim na prova a seguir; mas é bom porque “Campeã da Europa e tal"...é uma sensação boa, é fixe...

Atleta 6

Um outro aspecto curioso que se pode ressaltar destes dados é que os atletas atribuíram relevância a emoções que não foram consideradas por Lazarus(30) na adaptação do seu modelo para o desporto, nomeadamente a tristeza, o medo e a frustração. Este aspecto deve ser tido em consideração em investigações futuras, concretamente no que diz respeito à investigação e avaliação psicológica no domínio das emoções no contexto desportivo.

Paralelamente, é também interessante constatar que emoções como a irritação/ raiva, geralmente consideradas negativas pela literatura da especialidade(e.g., 23), nem sempre são vistas dessa forma pelos atletas. Aliás, parece que se passa com esta emoção o mesmo que acontece com a ansiedade, que uns atletas consideram positiva e outros negativa. Em estudos futuros, será oportuno analisar se esta percepção estará relacionada com estratégias de coping e/ ou percepção de controlo.

Por outro lado, o facto da vergonha, a tristeza e o medo terem sido consistentemente considerados negativos é um aspecto a não negligenciar em termos práticos - i.e., na intervenção com atletas nomeadamente no que respeita ao desenvolvimento de estratégias de coping e gestão das emoções. O mesmo raciocínio deverá ser aplicado à euforia, referida como negativa devido ao seu poder de provocar desconcentração. Não obstante este facto necessitar de ser comprovado em estudos futuros, esta referência pode constituir um alerta importante para técnicos e consultores a intervirem directamente com atletas. 


\section{CONCLUSÕES E IMPLICAÇÕES}

A presente investigação pretendia, recorrendo a entrevistas aprofundadas, identificar as principais fontes de stress e estratégias de coping a que atletas de elite recorriam em situações stressantes e/ ou problemáticas, bem como explorar o papel de outras emoções no seu desempenho desportivo.

A metodologia escolhida justifica-se pela necessidade de se aprofundarem os estudos de natureza quantitativa realizados anteriormente e, porque, nos últimos anos, tem sido uma abordagem cada vez mais sugerida por alguns investigadores no domínio da psicologia do desporto(e.g., 11, 15, 16). Importa salientar, porém, que não obstante permitirem o acesso a informação dificilmente conseguida de outra forma, as investigações qualitativas e, especificamente, a comparação dos resultados com outros estudos de cariz qualitativo, tem limitações. Com efeito, já diversos investigadores alertaram para que as comparações entre estudos qualitativos, apesar de necessárias e desejáveis, devem ser realizadas com algum cuidado, pois diferenças no paradigma da investigação qualitativa ao nível das entrevistas, observações, natureza e limites da amostra e abordagens metodológicas podem, em alguns casos, aumentar a probabilidade de gerar respostas e categorias distintas $(16,26)$. Por outro lado, como afirmaram Krane et al.(29), "esperar similaridade entre os investigadores qualitativos seria uma 'codificação prematura' da 'forma correcta de fazer trabalho qualitativo' "(p. 217). Todos estes aspectos sugerem assim um cuidado e atenção especiais na comparação dos resultados.

A análise dos dados relacionados com as principais fontes de stress e ansiedade experienciadas pelos sujeitos deste estudo permitiu a identificação de dimensões gerais que eram, de uma forma geral, consistentes com investigações anteriores neste domínio. Além disso, apesar de os atletas estarem envolvidos em diferentes modalidades, algumas fontes de stress eram partilhadas, designadamente no que concerne à natureza da competição, pressões externas ou a preocupação com o facto de não terem o desempenho esperado.

No que diz respeito às estratégias de coping, a presente investigação vem ao encontro de afirmações de Folkman e Lazarus(12) e Gould et al.(15, 16), segundo os quais as estratégias de coping não estão limitadas a estratégias específicas para lidar com um stressor específico. De facto, as análises efectuadas mostraram que os sujeitos recorriam simultaneamente a diversas estratégias de coping e não apenas a uma, podendo estas ser centradas na resolução de problemas e/ ou na gestão das emoções, adaptativas e/ ou desadaptativas. Em concreto, os atletas recorriam principalmente ao coping activo, à reavaliação positiva e ao planeamento, todas estratégias consideradas adaptativas, mas também referiram o recurso a algumas estratégias desadaptativas (e.g., desistir/ desinvestir; coping confrontativo).

Assim, dado que este estudo sugere que os atletas de elite recorrem a um vasto leque de estratégias de coping, consideramos ser interessante desenvolver estudos longitudinais que possibilitem o estabelecimento de uma relação entre as fontes de stress e as estratégias de coping geralmente utilizadas para lidar com as mesmas. Por outro lado, parece ser evidente a monitorização de uma possível natureza dinâmica das respostas de coping ao longo da época e a análise da eficácia de intervenções ao nível do coping. Vários autores (e.g., 15, 16, 24) sugeriram que, no desporto, os atletas podem usar diferentes estratégias de coping em diferentes fases do ciclo competitivo e de acordo com as exigências da situação, sendo por isso recomendado que, futuramente, sejam conduzidos estudos longitudinais em que tenham lugar múltiplas entrevistas ao longo da época ou em múltiplas épocas e em diferentes contextos de rendimento (e.g., competições fáceis/ difíceis; lesões); desta forma, as ligações entre o uso de estratégias de coping, redução ou gestão do stress e rendimento podiam ser mais clarificadas. Adicionalmente, a realização deste género de estudos qualitativos e longitudinais também poderá ajudar os investigadores a ultrapassarem as limitações de entrevistas retrospectivas isoladas, nomeadamente no que respeita à precisão dos resultados recordados, ou à influência dos resultados das competições na recordação das percepções de eficácia das estratégias utilizadas.

Por outro lado, pelo menos uma das estratégias de coping reveladas pelos atletas nas entrevistas realizadas (e.g., coping confrontativo) não é especificamente medida por instrumentos de avaliação quantitativa, como o é o caso do Brief COPE (ver 3). Parecem assim justificar-se as advertências de Crocker et al.(8), para 
os "perigos" dos principais instrumentos usados para medir o coping no desporto não terem sido originalmente desenvolvidos com populações desportivas e, consequentemente, não terem em linha de conta outras estratégias de coping específicas resultantes da interacção dos atletas com o seu ambiente social. Este dado poderá sugerir as potencialidades do desenvolvimento de instrumentos de avaliação do coping contextualmente sensíveis.

Uma outra área potencialmente importante para investigações futuras diz respeito à análise de estratégias de coping específicas em termos da sua (in)eficácia. Com efeito, Gould et al.(15) sugeriram que a estratégia utilizada pode não ser tão importante quanto a capacidade do atleta para a iniciar e usar de forma automática. Neste contexto, há também necessidade de se desenvolverem investigações sobre a intervenção no âmbito do ensino ou promoção de estratégias de coping, com o propósito de ensinar, aos atletas, estratégias associadas a um coping bem-sucedido (e, especialmente, fazer com que os atletas aprendam essas estratégias de forma a que se tornem automáticas). Neste sentido, comparações de atletas sujeitos a intervenção com outros incluídos em grupos de controlo permitirão aos investigadores identificar relações mais precisas entre o uso de estratégias de coping e o rendimento. Em face da existência de diferenças individuais nas respostas de coping dos atletas, torna-se também imperativo que estas sejam analisadas de forma aprofundada.

Por outro lado, a percepção de controlo pode constituir um factor determinante no potencial efeito debilitativo ou facilitativo da ansiedade no rendimento, pelo que entendemos que deverá ser um aspecto importante a incluir em futuros estudos. Segundo Carver e Scheier(4), se os indivíduos se sentem no controlo de uma situação problemática, terão expectativas positivas para lidar com a mesma e atingirem os seus objectivos e, por isso, responderão com uma focalização aumentada na tarefa (e.g., aumento do esforço, maior persistência, maiores níveis de rendimento); em contrapartida, se percepcionam uma incapacidade de se controlarem a si próprios ou ao seu ambiente, muito provavelmente duvidarão das suas capacidades de coping, o que pode gerar ansiedade e consequente diminuição do esforço, desviando o atleta da tarefa. O recurso a uma metodologia qua- litativa para investigar possíveis relações entre a percepção de controlo e as estratégias de coping em situações elicitadoras de ansiedade deverá ser, assim, um aspecto a contemplar futuramente.

$\mathrm{Na}$ mesma linha, considerando que emoções como a irritação/ raiva ou o orgulho assumiram, neste estudo, um papel ambíguo - variando o seu valor e utilidade em função da situação e/ ou do indivíduo importará tentar relacionar as emoções de atletas não só com as estratégias de coping (eficácia, automaticidade), mas também com a percepção de controlo. Na presente investigação, foi evidente que os atletas experimentavam diversos estados emocionais para além da ansiedade (e.g., irritação/ raiva, vergonha, felicidade, tristeza) e que o estudo isolado desta emoção poderá ser algo "redutor" se o que se pretende é promover o desempenho desportivo. Neste contexto, esta linha de investigação poderá permitir compreender melhor o papel de diferentes estados emocionais no desempenho desportivo - um domínio sobre o qual, como foi anteriormente referido, o conhecimento é ainda escasso - e, posteriormente, desenvolver programas de auto-regulação emocional que incluam não só a ansiedade, mas também outras emoções.

Em suma, o presente estudo, recorrendo a uma metodologia qualitativa, permitiu evidenciar a emergência do importante papel que outras emoções e/ou reacções emocionais, para além da ansiedade, parecem desempenhar e assumir na competição desportiva, reforçando assim a necessidade de uma abordagem mais ampla e integradora neste domínio de investigação. Na verdade, parece ser evidente que a compreensão do fenómeno da ansiedade, bem como de muitas outras emoções, porque surgem e actuam num contexto que por si só é altamente complexo e multifacetado, poderá ser melhorada se reconhecermos que ela(s) integra(m) um sistema de múltiplas variáveis interdependentes (incluindo variáveis pessoais e contextuais), devendo por isso ser consideradas, desejavelmente, de forma combinada e/ ou em simultâneo. 


\section{AGRADECIMENTOS}

Esta investigação foi realizada com o apoio da Fundação para a Ciência e a Tecnologia (Ministério da Ciência, Tecnologia e Ensino Superior), através da bolsa PRAXIS XXI/BD/20022/99.

\section{CORRESPONDÊNCIA}

\section{Cláudia Dias}

Gabinete de Psicologia do Desporto

Faculdade de Desporto, Universidade do Porto

Rua Dr. Plácido Costa, 91

4200-450 Porto

Portugal

E-mail: cdias@fade.up.pt 


\section{BIBLIOGRAFIA}

1. Anshel MH, Wells B. (2000). Sources of acute stress and coping styles in competitive sport. Anxiety, Stress, and Coping: An International Journal 13: 1-26.

2. Barbosa LG, Cruz JF (1997). Estudo do stress, da ansiedade e das estratégias de coping psicológico no andebol de alta competição. Psicologia: Teoria, Investigação e Prática 2: 523 548.

3. Carver CS (1997). You want to measure coping but your protocol's too long: Consider the Brief Cope. International Journal of Behavioral Medicine 4(1): 92-100.

4. Carver CS, Scheier MF (1994). Situational coping and coping dispositions in a stressful transaction. Journal of Personality and Social Psychology 66: 184-195.

5. Carver CS, Scheier MF, Weintraub JK. (1989). Assessing coping strategies: A theoretically based approach. Journal of Personality and Social Psychology 56: 267-283.

6. Crocker PR (1992). Managing stress by competitive athletes: Ways of coping. International Journal of Sport Psychology 23: 161-175.

7. Crocker PR, Graham TR (1995). Coping by competitive athletes with performance stress: Gender differences and relationships with affect. The Sport Psychologist 9: 325-338.

8. Crocker PR, Kowalski KC, Graham TR. (1998). Measurement of coping strategies in sport. In: Duda JL (ed.). Advances in sport and exercise psychology measurement. Morgantown: Fitness Technology Inc., 149-161.

9. Cruz JF. (1996). Stress, ansiedade e rendimento na competição desportiva. Braga: Centro de Estudos em Educação e Psicologia, Instituto de Educação e Psicologia, Universidade do Minho.

10. Dale GA. (2000). Distractions and coping strategies of elite decathletes during their most memorable performances. The Sport Psychologist 14: 17-41.

11. Edwards T, Kingston K, Hardy L, Gould D. (2002). A qualitative analysis of catastrophic performances and the associated thoughts, feelings and emotions. The Sport Psychologist 16: 1-19.

12. Folkman S, Lazarus RS (1985). If it changes it must be a process: Study of emotion and coping during three stages of a college examination. Journal of Personality and Social Psychology 48, 150-170.

13. Giacobbi PR, Weinberg RS. (2000). An examination of coping in sport: Individual trait anxiety differences and situational consistency. The Sport Psychologist 14: 42-62.

14. Gould D, Eklund RC, Jackson SA. (1992). 1988 U. S. Olympic wrestling excellence: I. Mental preparation, precompetitive cognition, and affect. The Sport Psychologist 6: 358-382.

15. Gould D, Eklund RC, Jackson SA (1993). Coping strategies used by U.S. Olympic wrestlers. Research Quarterly for Exercise and Sport 64: 83-93.

16. Gould D, Finch LM, Jackson SA (1993). Coping strategies used by national champion figure skaters. Research Quarterly for Exercise and Sport 64: 453-468.

17. Gould D, Jackson SA, Finch LM (1993). Sources of stress in national champion figure skaters. The Sport Psychologist 7: 354-374.
18. Gould D, Krane V (1992). The arousal-athletic performance relationship: Current status and future directions. In: Horn TS (ed.). Advances in sport psychology. Champaign IL: Human Kinetics, 119-141.

19. Gould D, Udry E (1994). The psychology of knee injuries and injury rehabilitation. In: Griffin LY (ed.). Rehabilitation of the injured knee. St. Louis MO: Mosby, 86-98.

20. Hammermeister J, Burton D (2001). Stress, appraisal, and coping revisited: Examining the antecedents of competitive state anxiety with endurance athletes. The Sport Psychologist 15: 66-90.

21. Hanin YL (2000). Introduction: An individualized approach to emotion in sport. In: Hanin YL (ed.). Emotions in sport. Champaign, IL: Human Kinetics, ix-xii.

22. Hanin YL (2000). Individual zones of optimal functioning (IZOF) model: Emotion-performance relationships in sport. In: Hanin YL (ed.). Emotions in sport. Champaign, IL: Human Kinetics, 65-89.

23. Hanin YL (2000). Successful and poor performance and emotions. In: Hanin YL (ed.). Emotions in sport. Champaign IL: Human Kinetics, 157-187.

24. Holt NL, Hogg JM (2002). Perceptions of stress and coping during preparation for the 1999 women's soccer world cup finals. The Sport Psychologist 16: 251-271.

25. Jackson S (1995). The growth of qualitative research in psychology. In: Morris TW, Summers J (eds.). Sport psychology: Theory, applications and issues. Milton QLD (Australia): Jacaranda Wiley, Ltd., 575-591.

26. James B, Collins D (1997). Self-presentational sources of competitive stress during performance. Journal of Sport and Exercise Psychology 19: 17-35.

27. Jones G (1991). Recent developments and current issues in competitive state anxiety research. The Sport Psychologist 4: 152-155.

28. Jones G, Hardy L (1990). Stress in sport: Conceptual considerations and effects upon performance. In: Jones G, Hardy L (eds.). Stress and performance in sport. Chichester (UK): John Wiley \& Sons, Inc., 247-277.

29. Krane V, Andersen MB, Strean WB (1997). Issues of qualitative research methods and presentation. Journal of Sport and Exercise Psychology 19: 213-218.

30. Lazarus RS (2000). How emotions influence performance in competitive sports. The Sport Psychologist 14: 229-252.

31. Mellalieu SD, Hanton S, Jones G (2003). Emotional labeling and competitive anxiety in preparation and competition. The Sport Psychologist 17: 157-174.

32. Roberts GC, Treasure DC (1995). Achievement goals, motivational climate, and achievement strategies and behaviours in sport. International Journal of Sport Psychology 26: 64-80.

33. Scanlan TK, Stein GL, Ravizza K (1991). An in-depth study of former elite figure skaters: 3 . Sources of stress. Journal of Sport and Exercise Psychology 13: 103-120.

34. Taylor J, Schneider BA (1992). The sport-clinical intake protocol: A comprehensive interviewing instrument for sport. Professional Psychology: Research and Practice 23: 318-325.

35. Weinberg R, Gould, D (1995). Foundations of sport and exercise psychology. Champaign IL: Human Kinetics. 